\title{
How Does the Periodic Groundwater Table Fluctuation Impact on Chlorinated Vapor Intrusion?
}

\author{
Honghong Zhang, Yu Ye $\mathbb{D}^{\text {, }}$, and Xin Yang \\ State Key Laboratory of Hydrology-Water Resources and Hydraulic Engineering, Hohai University, Nanjing, China \\ Correspondence should be addressed to Yu Ye; yeyu@hhu.edu.cn
}

Received 5 November 2020; Revised 8 February 2021; Accepted 24 February 2021; Published 8 March 2021

Academic Editor: Richeng Liu

Copyright (c) 2021 Honghong Zhang et al. This is an open access article distributed under the Creative Commons Attribution License, which permits unrestricted use, distribution, and reproduction in any medium, provided the original work is properly cited.

\begin{abstract}
Periodic groundwater table fluctuations are found frequently in natural aquifers due to sea tides or seasonal recharge. However, their impact on the transport of volatile organic compounds in the vadose zone released from a groundwater contaminant source (i.e., vapor intrusion) has not been well known. A 2D numerical model was developed to explore vapor intrusion processes in the sandy vadose zone, subject to a fluctuating groundwater table with a range of fluctuation amplitudes and periods. A carcinogenic compound, Trichloroethylene (TCE), was chosen as the groundwater contaminant of interest in the current study and assumed to transport into the dwelling through a crack at the corner of the basement. Results showed that the resistant effect caused by high soil moisture contents in the thin capillary fringe is weakened by periodic groundwater table fluctuations, resulting in a higher concentration of gaseous TCE at the building foundation crack, in comparison with that under a static groundwater table. The increase of the gaseous TCE concentration was induced by the enhancement of diffusion and advection due to groundwater table fluctuations. Sensitivity analyses indicated that a higher amplitude and frequency of fluctuations lead to a higher TCE concentration at the crack under the dynamic equilibrium condition. Specifically, compared with the static groundwater table condition, the TCE concentration at the crack increased by one order of magnitude under the condition of groundwater table fluctuations with an amplitude of $0.2 \mathrm{~m}$ and a period of one day. The results obtained could provide insights into the importance of the amplitude and frequency of groundwater table fluctuations on vapor intrusion.
\end{abstract}

\section{Introduction}

Soil and groundwater contaminated by volatile organic compounds (VOCs) are suspected to have the carcinogenic risk and have caused a lot of public health issues $[1,2]$. The dynamic process of contaminants migrating through the unsaturated zone, entering into buildings located above, and threatening the health of human beings is called vapor intrusion (e.g., [3-10]). This process should not be neglected when evaluating the potential health risk and determining the solution to remediate contaminated sites. The contaminated groundwater is usually assumed as the source of toxic vapor for its greater scale of contaminant plume compared with the nonaqueous phase liquid (NAPL) source. Numerous studies have shown that the groundwater table could keep fluctuating because of the influence of rainfall infiltration, pumping, tides, and so on (e.g., [11-13]). According to vapor intrusion guidelines [14-17], fluctuations of the groundwater table can influence the migration of contaminants through the unsaturated zone. Consequently, this phenomenon will alter the distribution and indoor concentration of contaminants. Hence, it is essential to have a good understanding of how groundwater table fluctuations affect vapor intrusion processes.

Fluctuations of the groundwater table can increase the impact of advection and dispersion compared with static scenarios. A number of studies have been performed to investigate the role of groundwater table fluctuations in the transport of vapor through the unsaturated zone (e.g., [18, 19]). McCarthy and Johnson [20] and Werner and Hohener [21] have argued that the gaseous contaminant concentration may increase when the groundwater table starts falling based on laboratory experiment results. A few numerical simulations have been conducted to explore how fluctuations of 
the groundwater table affect the vapor concentration in the vadose zone and demonstrated that the soil gas concentration could be underestimated without the consideration of groundwater table fluctuations [22, 23]. Despite that these studies preliminarily identified the potential effect of groundwater table fluctuations on the transport of VOCs, a comprehensive investigation on the impact of the fluctuation amplitude and period on attenuation processes of the vapor concentration is not currently available.

The objective of this paper is to systematically investigate the vapor concentration distribution in the unsaturated zone and the changing process of the gaseous contaminant concentration at the building foundation crack subject to groundwater table fluctuations with a range of amplitudes and periods. In reality, daily and seasonal oscillations of the groundwater table are ubiquitous and the amplitudes of groundwater table fluctuations could range from several centimeters to meters [24-26]. In order to achieve this objective, a 2D numerical model is developed using COMSOL Multiphysics. Trichloroethylene (TCE), a carcinogenic compound and one of the most frequently detected contaminants, is chosen as the major contaminant [27-29]. TCE is classified as a recalcitrant chemical, which means it is a continuous source, hard to be biodegraded, and capable of threatening human health for an elongated period [16]. Groundwater which dissolves gaseous TCE is assumed as the source of contaminant. Our study is expected to offer important insights into vapor intrusion processes under the effect of groundwater table fluctuations in natural aquifers.

\section{Numerical Modeling}

2.1. Governing Equations. A $2 \mathrm{D}$ numerical model is built to investigate the influence of groundwater table fluctuations on vapor intrusion using a finite element code COMSOL Multiphysics, which has been widely adopted in previous studies to solve the problem of vapor transport from the contaminant source to the dwelling through the building foundation crack (e.g., [30-33]). The development and use of this code to solve typical vapor intrusion problems have been described in detail in Pennell et al. [30]. The grids in this model can be transformed freely to adapting to the fluctuation of the groundwater table.

The water flow in variably saturated porous media can be described by the Richards' equation:

$$
\left(\frac{C_{m}}{\rho g}+S_{e w} S\right) \frac{\partial p}{\partial t}+\vec{\nabla}\left[-\frac{k_{s}}{\mu} k_{r}(\vec{\nabla} p+\rho g \vec{z})\right]=0
$$

where $C_{m}\left(\mathrm{~m}^{-1}\right)$ is the specific moisture capacity, $S_{e w}$ is the effective saturation, $S\left(\mathrm{~m}^{-1}\right)$ is the storage coefficient, $k_{s}$ $\left(\mathrm{m}^{2}\right)$ is the intrinsic permeability, $k_{r}(-)$ is the relative permeability, $\mu(\mathrm{Pa} \cdot \mathrm{s})$ is the fluid dynamic viscosity, $\rho\left(\mathrm{kg} / \mathrm{m}^{3}\right)$ is the fluid density, $g\left(\mathrm{~m} / \mathrm{s}^{2}\right)$ is the acceleration of gravity, $z(\mathrm{~m})$ is the elevation, and $p(\mathrm{~Pa})$ is the pressure.
The velocity vector of fluid can be calculated by

$$
\vec{u}=-\frac{k_{s}}{\mu} k_{r}(\vec{\nabla} p+\rho g \vec{z})
$$

The analytical formulas of van Genuchten are frequently used in variably saturated flow modeling. The moisture content distribution and specific moisture capacity can be approximated by the van Genuchten equation as follows [34]:

$$
\begin{aligned}
& S_{e w}= \begin{cases}\frac{1}{\left[1+\left|\alpha H_{p}\right|^{N}\right]^{M}} & H_{p}<0 \\
1 & H_{p} \geq 0\end{cases} \\
& \theta_{w}= \begin{cases}\theta_{r}+S_{e w}\left(\theta_{t}-\theta_{r}\right) & H_{p}<0 \\
\theta_{t} & H_{p} \geq 0\end{cases} \\
& C_{m}=\left\{\begin{array}{ll}
\frac{\alpha M}{1-M}\left(\theta_{t}-\theta_{r}\right) S_{e w}^{1 / M}\left(1-S_{e w}^{1 / M}\right)^{M} & H_{p}<0 \\
0 & H_{p} \geq 0
\end{array},\right.
\end{aligned}
$$

where $H_{p}(\mathrm{~m})$ is the pressure head, $H_{p}=p / \rho g ; \theta_{t}(-), \theta_{w}(-)$, and $\theta_{r}(-)$ are the total porosity, water content, and residual soil water content, respectively; $\alpha\left(\mathrm{m}^{-1}\right)$ is the point of inflection in the water retention curve where $d \theta_{w} / d z$ is maximal; and $N$ and $M$ are the van Genuchten curve shape parameters, $M=1-1 / N$. Note that $\theta_{r}$ represents the water content of a soil where a further increase in negative pore-water pressure does not produce significant changes in water content.

Given the moisture content distribution, the relative permeability could be calculated in the following form [35]:

$$
\begin{aligned}
& k_{r, g}=\left(1-s_{e w}\right)^{0.5}\left[1-s_{e w}^{1 / M}\right]^{2 M}, \\
& k_{r, w}=s_{e w}^{0.5}\left[1-\left(1-s_{e w}^{1 / M}\right)^{M}\right]^{2},
\end{aligned}
$$

where $k_{r, g}$ and $k_{r, w}$ are the relative permeability of soil gas and water compared to the intrinsic permeability, respectively.

The spatial and temporal variations of contaminant concentration can be described by the transport equation:

$$
\left(\theta_{g}+\frac{\theta_{w}}{K_{H}}\right) \frac{\partial c}{\partial t}=\vec{\nabla}\left[\left(D_{e}+\alpha_{L}|u|\right) \vec{\nabla} c\right]-\vec{\nabla}(\vec{u} c)
$$

where $\theta_{g}(-)$ is the gas content and equals to $\theta_{\mathrm{t}}-\theta_{\mathrm{w}}, K_{H}$ is the Henry's law constant, $c(\mathrm{mg} / \mathrm{L})$ is the concentration of contaminant, $D_{e}\left(\mathrm{~m}^{2} / \mathrm{s}\right)$ is the effective diffusivity coefficient, and $\alpha_{L}(\mathrm{~m})$ is the longitudinal dispersivity.

The effective diffusivity in the soil is a function of moisture content, and it can be approximated by using the Millington and Quirk model as [36]

$$
D_{e}=D_{g} \frac{\theta_{g}^{10 / 3}}{\theta_{t}^{2}}+\frac{D_{w}}{K_{H}} \frac{\theta_{w}^{10 / 3}}{\theta_{t}^{2}}
$$




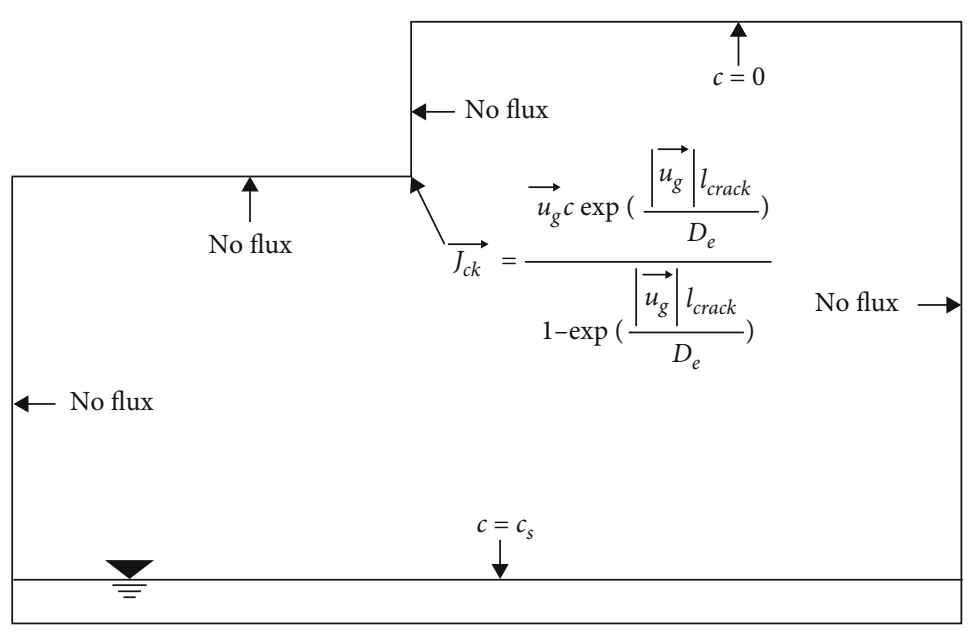

Figure 1: The schematic of the conceptual model.

TABle 1: Parameters inputted in the simulation.

\begin{tabular}{lc}
\hline Parameter & Value \\
\hline Foundation crack width $\left(w_{c k}\right)$ & $0.001 \mathrm{~m}$ \\
Foundation footprint length & $10 \mathrm{~m}$ \\
Foundation depth $\left(d_{f}\right)$ & $2 \mathrm{~m}$ \\
Basement slab thickness $\left(l_{\text {slab }}\right)$ & $0.15 \mathrm{~m}$ \\
Field length & $24 \mathrm{~m}$ \\
Mean water table level $\left(h_{m}\right)$ & $-8 \mathrm{~m}$ \\
Groundwater $($ source $)$ concentration $\left(c_{s}\right)$ & $0.540 \mathrm{mg} / \mathrm{L}$ \\
Henry's constant $\left(K_{H}\right)$ & 0.403 \\
Diffusion coefficient in gas $\left(D_{g}\right)$ & $6.87 \times 10^{-6} \mathrm{~m}^{2} / \mathrm{s}$ \\
Diffusion coefficient in water $\left(D_{w}\right)$ & $1.02 \times 10^{-9} \mathrm{~m}^{2} / \mathrm{s}$ \\
Soil porosity $\left(\theta_{t}\right)$ & 0.375 \\
Residual water content $\left(\theta_{r}\right)$ & 0.053 \\
Van Genuchten parameter $(N)$ & 3.177 \\
Van Genuchten parameter $(M)$ & 0.685 \\
Van Genuchten parameter $(\alpha)$ & $3.524 \mathrm{~m}^{-1}$ \\
Intrinsic permeability $\left(k_{s}\right)$ & $9.9 \times 10^{-12} \mathrm{~m}^{2}$ \\
Longitudinal dispersivity $\left(\alpha_{L}\right)$ & $0.001 \mathrm{~m}$ \\
Groundwater table fluctuation period $(T)$ & $1,30,365 \mathrm{~d}$ \\
Groundwater table fluctuation amplitude $(A)$ & $0.01,0.05,0.1,0.2 \mathrm{~m}$ \\
\hline
\end{tabular}

where $D_{g}\left(\mathrm{~m}^{2} / \mathrm{s}\right)$ and $D_{w}\left(\mathrm{~m}^{2} / \mathrm{s}\right)$ are the molecular diffusivity of contaminant in gas and water phase, respectively.

Note that sorption is not considered in this model for a low soil organic fraction measured in the sand medium [18]. Biodegradation is not taken into account in chlorinated vapor intrusion for the reason that TCE is a recalcitrant chemical in aerobic environments [16].

2.2. Conceptual Model. A scenario with a basement as the building of interest is assumed as the conceptual model in our study. The basement is assumed to be $10 \mathrm{~m}$ long and $2 \mathrm{~m}$ high, and it is located $2 \mathrm{~m}$ beneath the soil surface.
Because of the symmetry, only half of the model is simulated, which is shown in Figure 1. A $0.001 \mathrm{~m}$ wide crack at the corner of the basement is regarded as the only entrance for vapor to transport into the dwelling. A flux boundary condition at the crack is used to meet the need for the continuity of contaminant emission [37]:

$$
\begin{aligned}
& \overrightarrow{J_{c k}}=D_{g} \frac{c}{l_{\text {slab }}} \text {, when } \overrightarrow{u_{g}}=0, \\
& \overrightarrow{J_{c k}}=\frac{\overrightarrow{u_{g}} c \exp \left(\left(\left|\overrightarrow{u_{g}}\right| / D_{g}\right) l_{\text {slab }}\right)}{1-\exp \left(\left(\left|\overrightarrow{u_{g}}\right| / D_{g}\right) l_{\text {slab }}\right)} \text {, when } \overrightarrow{u_{g}} \neq 0,
\end{aligned}
$$

where $\overrightarrow{J_{c k}}\left(\mathrm{mg} / \mathrm{m}^{2} \mathrm{~d}\right)$ is the flux of gaseous contaminant transporting through crack, $\overrightarrow{u_{g}}(\mathrm{~m} / \mathrm{s})$ is the velocity vector of fluid, and $l_{\text {slab }}(\mathrm{m})$ is the thickness of basement slab, and set to $0.15 \mathrm{~m}$ in this study.

The boundary conditions of basement walls are assumed as no-flux boundaries, the same as the vertical axis of symmetry and the right vertical boundary. The ground surface is regarded as an open boundary. The gaseous contaminant concentration is set to zero, and the pressure is equal to the atmospheric pressure. The groundwater contaminated by TCE is assumed as an infinite source of the toxic vapor, which means the concentration of the source keeps constant. Moreover, we assume that the transport of gas only occurs in the unsaturated zone. In other words, gas is not allowed to transport through the groundwater table.

Previous studies suggest that the groundwater table depth plays an insignificant role in a sandy vadose zone, since the upward soil gas transport is dominantly controlled by the rate through the layer with the highest resistance (e.g., [29]). Hence, the mean level of the groundwater table is assumed to be fixed at $8 \mathrm{~m}$ below the soil surface, which is deep enough to minimize its impact on gas transport. We consider the groundwater table as a sinusoidal function of time with a range of amplitudes $(0.01 \mathrm{~m}, 0.05 \mathrm{~m}, 0.1 \mathrm{~m}$, and 


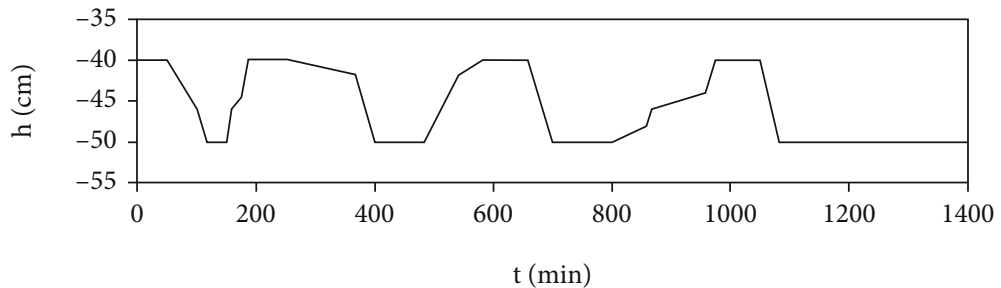

(a)

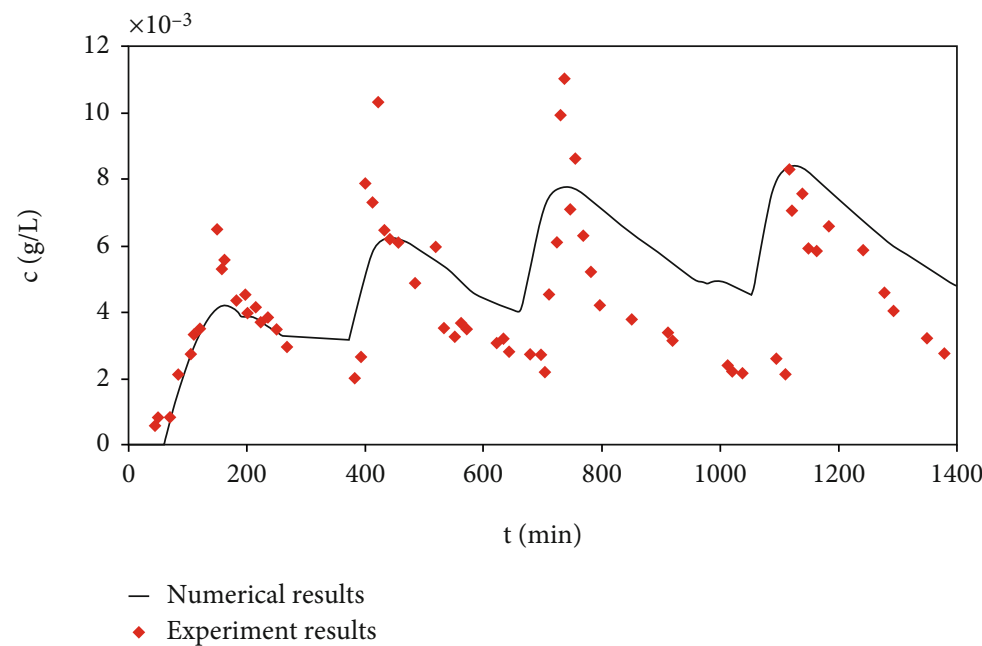

(b)

FIGURE 2: Comparison between experimental and numerical results.

$0.2 \mathrm{~m}$ ) and periods (one day, one month, and one year), which can be expressed as

$$
h=h_{m}+A \sin \left(\frac{2 \pi t}{T}\right),
$$

where $A(\mathrm{~m})$ and $T$ (day, month, or year) represent the amplitude and period of the sinusoidal fluctuation, respectively, and $h_{m}(\mathrm{~m})$ is the mean level of water table, which is $-8 \mathrm{~m}$ in this study. The parameter function (i.e., Eq. (8)) is used to determine the water table position at different times, while the moving mesh application is employed to determine the initial groundwater table position based on the zero pressure head contour.

The parameters together with the values used in simulations are listed in Table 1. The parameters of the foundation (such as the width of crack, footprint length, foundation depth, and field length) are determined according to values used in the document published by USEPA in 2012 [16]. The sand is chosen as the porous medium of this model, and the van Genuchten parameters listed here are taken from the USEPA spreadsheet [38]. The intrinsic permeability based on the soil type is assumed to be constant. The differences between the basement pressure and atmospheric pressure are not considered in this study.

The conceptual model considered in our study is simplified and idealized and neglects a number of factors, which could occur in reality. For example, the heterogeneity of the soil media, rainfall recharge, and the temporal variation of the atmospheric pressure, surface temperature, and source concentration is not considered. Moreover, the model is simplified as two dimensional, while a 3D model may be needed when assessing a real case.

\section{Results and Discussion}

3.1. Model Verification. Joun et al. [39] carried out 2D sand tank experiments to study the impact of groundwater table fluctuations on the gaseous TCE concentration in the unsaturated zone. The sand tank, measuring $60 \mathrm{~cm}$ in length (inside), $50 \mathrm{~cm}$ in height, and $4 \mathrm{~cm}$ in width, was filled with sands and covered by a clay material. The intrinsic permeability, porosity, and bulk density of soil obtained in the laboratory are $9.7 \times 10^{-11} \mathrm{~m}^{2}, 0.37$, and $1.55 \mathrm{~g} / \mathrm{cm}^{3}$, respectively. The groundwater contaminated by TCE is chosen as the source of toxic vapor. The concentration of contaminated groundwater is $10 \mathrm{mg} / \mathrm{L}$. The groundwater table elevation varies between $40 \mathrm{~cm}$ and $50 \mathrm{~cm}$ below the soil surface, as shown in Figure 2(a). A Teflon pipe was used to extract air and TCE gas from the sand tank. The soil air containing TCE gas was sampled through a bypass tube at the top of the Teflon pipe at a sampling time interval of $5 \mathrm{~min}$. A Teflon pipe, which is inactive to chloride solvents, was installed at the center of the sandbox and screened at depth intervals of 18 and $23 \mathrm{~cm}$ from the tank bottom.

We numerically simulated the laboratory experiments and keep the setup parameters identical. Figure 2(b) shows the comparison of vapor concentration between experimental 


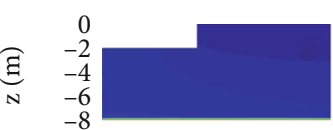

(a)

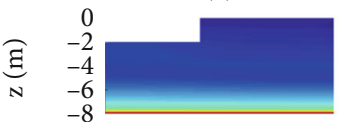

(d)

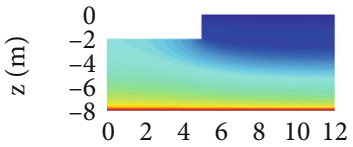

$\mathrm{x}(\mathrm{m})$

(g)

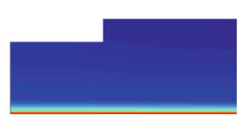

(b)

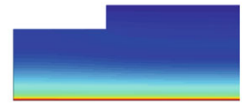

(e)

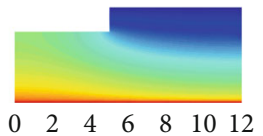

$\mathrm{x}(\mathrm{m})$

(h)

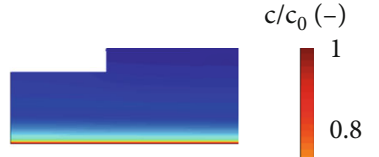

(c)

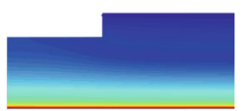

(f)

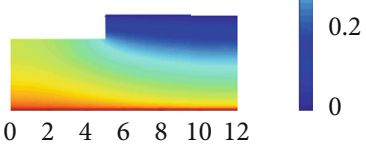

$\mathrm{x}(\mathrm{m})$

(i)

Figure 3: Transient distributions of gaseous TCE concentration in the vadose zone at $t=$ (a) $0 \mathrm{~d}$, (b) $10 \mathrm{~d}$, (c) $20 \mathrm{~d}$, (d) $30 \mathrm{~d}$, (e) $40 \mathrm{~d}$, (f) $50 \mathrm{~d}$, (g) $100 \mathrm{~d},(\mathrm{~h}) 200 \mathrm{~d}$, and (i) $400 \mathrm{~d}$, where the groundwater table is located $8 \mathrm{~m}$ below the ground surface, and the amplitude and period of the fluctuation are $0.2 \mathrm{~m}$ and one day, respectively.

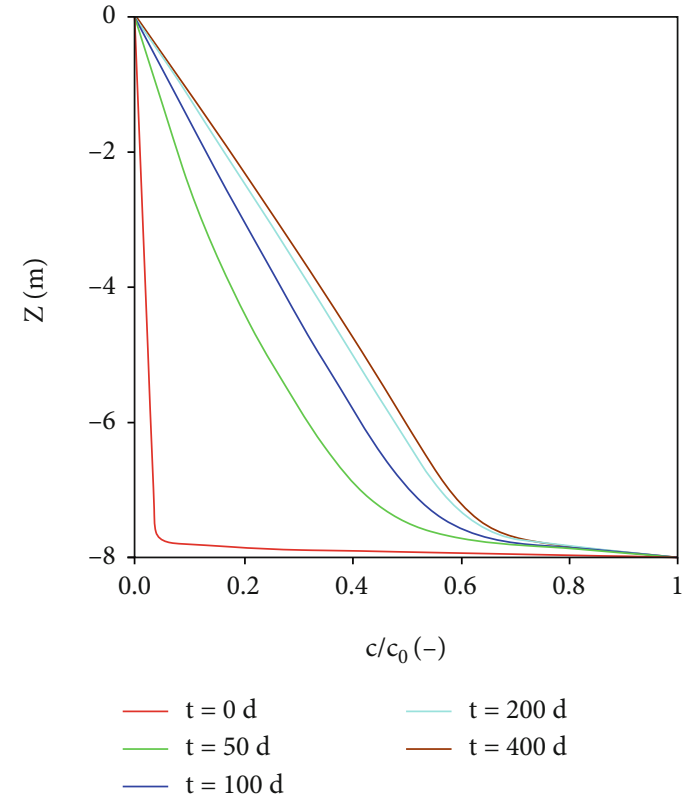

Figure 4: Transient vertical distributions of normalized gaseous TCE concentration at $x=10 \mathrm{~m}$.

and numerical results during 1400 minutes. Generally, as shown, the variation of gaseous TCE concentrations calculated by our numerical model matches well with experimental measurements. The maximum values of experiment results are larger than the counterpart in numerical results, while the minimum values of experimental results are smaller than the corresponding numerical results. This may be partly attributed to trapped gas bubbles in contaminated groundwater during the experiment, while they are not considered in numerical simulations. Other unknown systematic errors may exist, causing the discrepancy between the numerical and experimental results.

3.2. Impact of Groundwater Table Fluctuations. Figure 3 shows the transient concentration distributions of gaseous

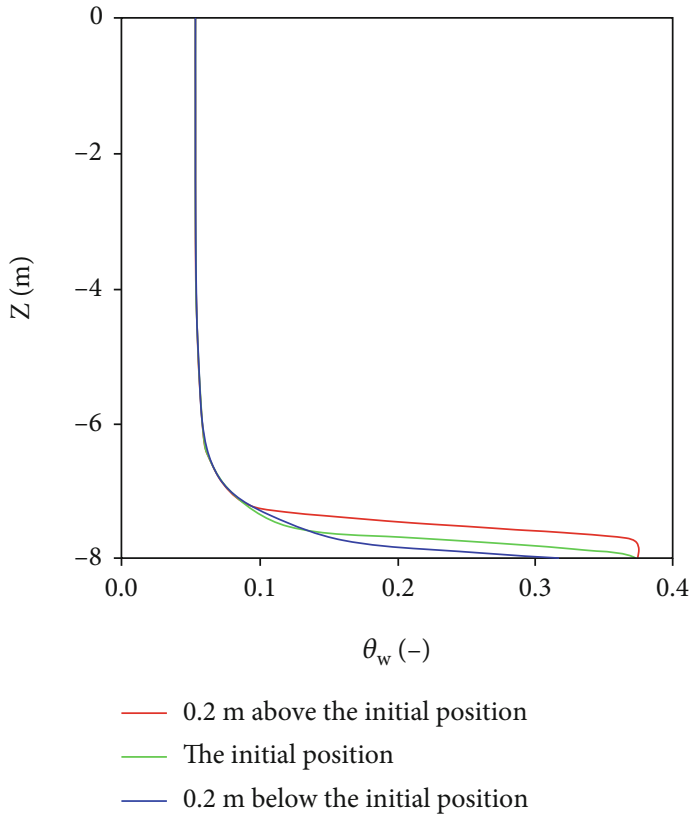

FIgURE 5: Vertical distributions of soil moisture content at $x=10 \mathrm{~m}$ under the dynamic equilibrium condition.

TCE, normalized by the vapor concentration in equilibrium with the contaminant source (i.e., the product of Henry's constant and groundwater source concentration), where the groundwater table is located $8 \mathrm{~m}$ below the ground surface, and the amplitude and period of the fluctuation are $0.2 \mathrm{~m}$ and one day, respectively. Before the groundwater table fluctuation, the normalized area-averaged concentration of vapor in the vadose zone is only 0.0524 (base case, Figure $3(\mathrm{a}))$. There is a large concentration gradient in the capillary fringe due to the high soil moisture distribution in this region, which is also illustrated in Figure 4. This phenomenon is called the "block" effect of the capillary fringe, resulting from the significant decrease in effective diffusion which has a negative correlation with the soil moisture content [20,40-42]. This can be mathematically 


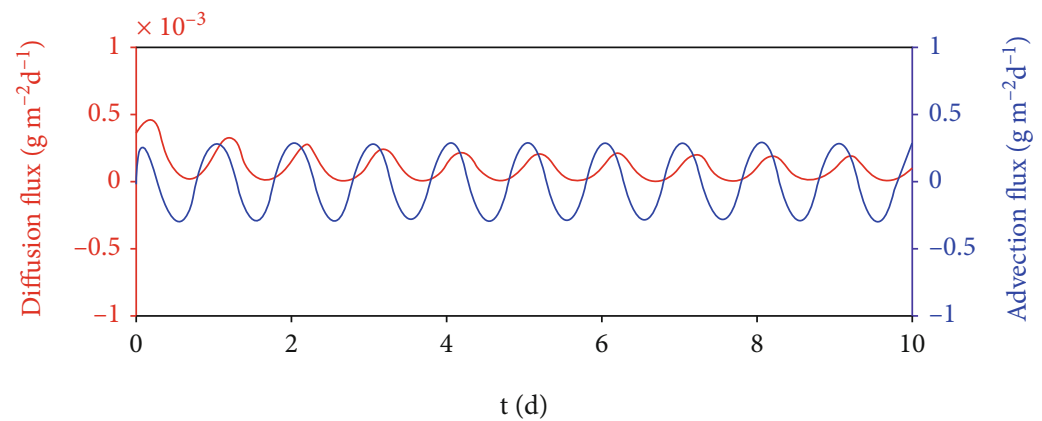

(a)

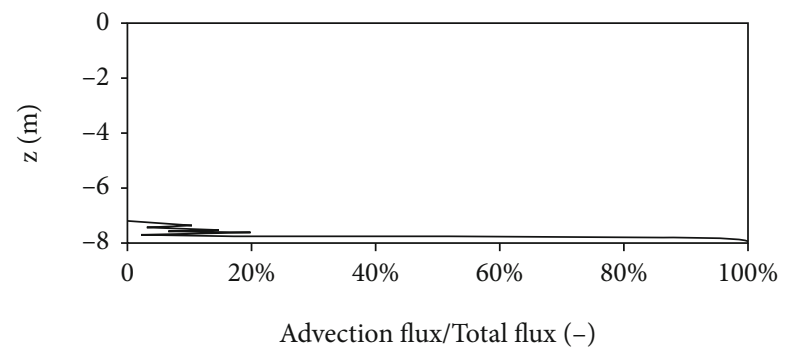

(b)

FIgURE 6: Fluxes caused by diffusion and advection at $x=10 \mathrm{~m}$, where $T=1 \mathrm{~d}$ and $A=0.2 \mathrm{~m}$ : (a) fluxes during the initial 10 days at $z=8 \mathrm{~m}$, and (b) the proportion of five-day averaged advection flux to the total mass flux under the dynamic equilibrium condition along the vertical direction.

explained by Eq. (6). Since $D_{g}$ is about three orders of magnitude larger than $D_{w}$, a larger $\theta_{w}$ (i.e., a smaller $\theta_{g}$ ) results in a smaller $D_{e}$.

Figures 3(b)-3(i) indicate that groundwater table fluctuations result in more toxic gas released from dissolved contaminant sources to the unsaturated zone, which would increase the health risk. As described above, the capillary fringe retards the release of gas from the source. Therefore, the results of Figures 3(b)-3(i) imply that the groundwater table fluctuations weaken the retardation capability of the capillary fringe in the migration of gaseous TCE. As clearly demonstrated in Figure 4, when the groundwater table fluctuations have not started (i.e., $t=0$ ), the gas concentration is significantly reduced across the capillary fringe (i.e., a high gas concentration gradient occurs within the capillary fringe). However, the concentration gradient within the capillary fringe becomes smaller with the groundwater table fluctuations and, finally, reaches a steady value. On one hand, the change of the groundwater level increases the concentration gradient near the groundwater table, which enhances the diffusion flux of contaminants. An incremental diffusion flux can be observed at the beginning of the groundwater fluctuation. The flux could decrease with the release of TCE and reach a dynamic equilibrium after several fluctuation periods. On the other hand, the water content keeps changing significantly in the capillary fringe as a result of groundwater table fluctuations (see Figure 5). Therefore, effective diffusion coefficients (see Eq. (6)) are adjusted accordingly because of the modified water content and gas content [43]. Particularly, under the condition of a falling groundwater table, the gas saturation of the capillary fringe is increased, leading to more contaminants exposed to the gas phase and easier transport of vapor through the capillary fringe.

Diffusion is regarded as the dominant migration mechanism for cases with a static groundwater table. However, according to the study of Guo and Jiao [44], airflow generated in the vadose zone due to sea tides could lead to the enhancement of advection. Figure 6(a) shows the fluxes caused by diffusion and advection at $x=10 \mathrm{~m}$ and $z=-8 \mathrm{~m}$, where $T=1 \mathrm{~d}$ and $A=0.2 \mathrm{~m}$, respectively. As illustrated in Figure 6(a), at the middle elevation of the groundwater table, the magnitude of the advection flux is about three orders higher than that of diffusion, indicating that advection dominates the vapor transport in the case with a fluctuating groundwater table. This is because that a fluctuating groundwater table drives the vapor transport at a high rate, hence leading to a high advective flux. By contrast, the phaseaveraged diffusion and advection fluxes are around $9.92 \times$ $10^{-2} \mathrm{~g} / \mathrm{m}^{2} \mathrm{~d}$ and $8.61 \times 10^{-14} \mathrm{~g} / \mathrm{m}^{2} \mathrm{~d}$ at the location $2 \mathrm{~m}$ above the groundwater table, respectively, suggesting that diffusion controls the vapor transport out of the range of groundwater table fluctuations. Above the fluctuation range of the groundwater table, water moves at a relatively slow speed, resulting in that the advective flux is small and vapor transport is driven largely by diffusion. As shown in Figure 6(b), diffusion is the dominant transport mechanism of vapor in the region above the capillary fringe, where the variation of soil moisture content is small and the distribution of vapor concentration in this zone is approximately linear (see Figures 4 and 5). This result is consistent with the findings of You and Zhan [45], in which the magnitude of advection flux is less 


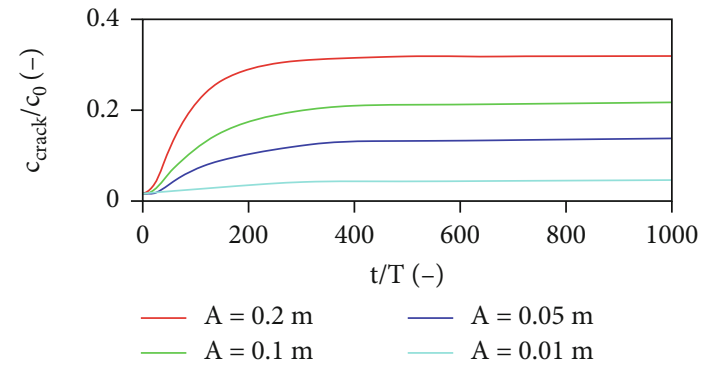

(a)

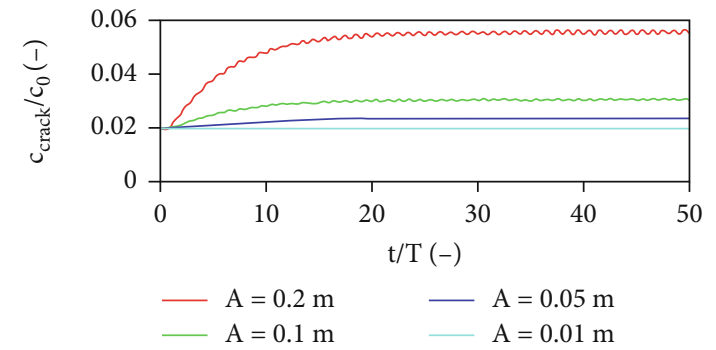

(b)

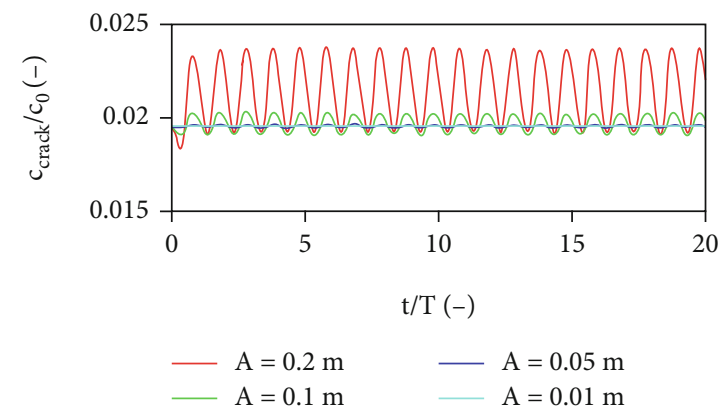

(c)

FIGURE 7: The variation of normalized gaseous TCE concentration at the crack for the cases with different fluctuation amplitudes and periods: (a) $T=$ one day, (b) $T=$ one month, and (c) $T=$ one year.

important than that of diffusion when the gas-filled porosity is more than 0.05 .

\subsection{Sensitivity of Fluctuation Amplitude and Period. Figure 7} shows the variation of gaseous TCE concentration at the crack for the cases with different fluctuation amplitudes (i.e., $A=0.01 \mathrm{~m}, 0.05 \mathrm{~m}, 0.1 \mathrm{~m}$, and $0.2 \mathrm{~m}$ ) and periods (i.e., $T=$ one day, one month, and one year), in which the time is normalized by the fluctuation period and the concentration is normalized by the source gaseous concentration. Table 2 lists corresponding gaseous TCE concentrations at the crack of the foundation under the dynamic equilibrium conditions. In general, as shown, both the amplitude and period of fluctuation play a significant role in vapor intrusion. Given the same fluctuation period, a larger fluctuation amplitude results in a larger gaseous TCE concentration under the dynamic equilibrium condition. By contrast, given the same fluctuation amplitude, a longer fluctuation period gives a smaller gaseous TCE concentration under the dynamic equilibrium condition. For example, the gaseous TCE concentration at the crack under the dynamic equilibrium condition is $0.069 \mathrm{mg} / \mathrm{L}$ for the case with $T=$ one day and $A=0.2 \mathrm{~m}$. This concentration is about 7 times as large as that of the case with $A=0.01$, and one order of magnitude higher than that of the case with $T=$ one year, under otherwise same condition.

The effect of the fluctuation period on the mass flux is due to that a higher fluctuation frequency can enhance advection. Simulation results show that the magnitude of the phase-averaged advection flux with $T=$ one day $(1.09 \times$ $\left.10^{-1} \mathrm{gm}^{2} \mathrm{~d}^{-1}\right)$ at $z=-8 \mathrm{~m}$ is about 3 orders higher than that with $T=$ one year $\left(1.32 \times 10^{-4} \mathrm{gm}^{2} \mathrm{~d}^{-1}\right)$. A higher mass flux means more gaseous TCE released to the unsaturated zone,
TABLE 2: The gaseous TCE concentration at the crack under the dynamic equilibrium 638 conditions for cases with different combinations of amplitude and period.

\begin{tabular}{lccc}
\hline Case & $A(\mathrm{~m})$ & $T(\mathrm{~d})$ & $c_{\text {crack }}(\mathrm{mg} / \mathrm{L})$ \\
\hline 1 & 0.2 & 1 & 0.069 \\
2 & 0.1 & 1 & 0.047 \\
3 & 0.05 & 1 & 0.030 \\
4 & 0.01 & 1 & 0.010 \\
5 & 0.2 & 30 & 0.012 \\
6 & 0.1 & 30 & 0.007 \\
7 & 0.05 & 30 & 0.005 \\
8 & 0.01 & 30 & 0.004 \\
9 & 0.2 & 365 & 0.005 \\
10 & 0.1 & 365 & 0.005 \\
11 & 0.05 & 365 & 0.004 \\
12 & 0.01 & 365 & 0.004 \\
13 & 0 & 0 & 0.004 \\
\hline
\end{tabular}

which results in a higher concentration at the crack. In addition, according to the study of Cartwright [46], the distribution of soil moisture above the groundwater table for a long oscillation period is similar to that for the static condition. As a result, the effective diffusion coefficient of gaseous TCE changes insignificantly in the case of $T=$ one year, and hence, the retardation function of the capillary fringe is largely kept.

The change of the gaseous TCE concentration at the crack in response to the groundwater table fluctuation is not instantaneous, especially for the case with a short fluctuation. As shown in Figure 8(a), for the case with $T=$ one day, 


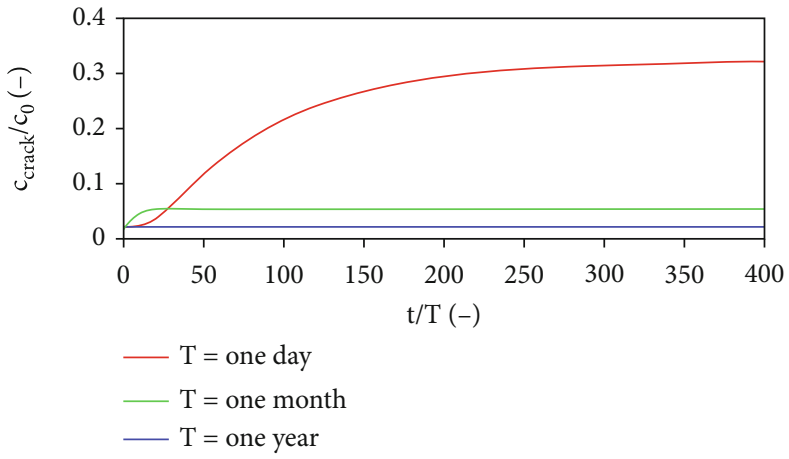

(a)

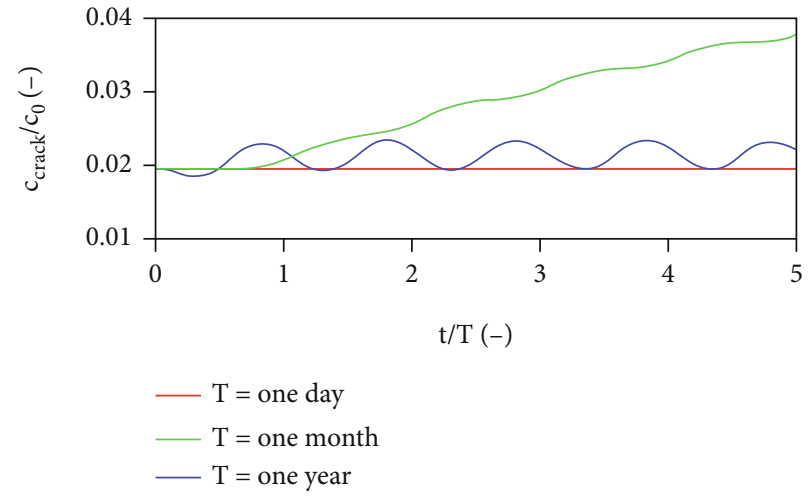

(b)

FIgURE 8: The variation of normalized gaseous TCE concentration at the crack for the cases with $A=0.2 \mathrm{~m}$ and different fluctuation periods ( $T$ = one day, one month, and one year): (a) 400 periods and (b) 5 periods.

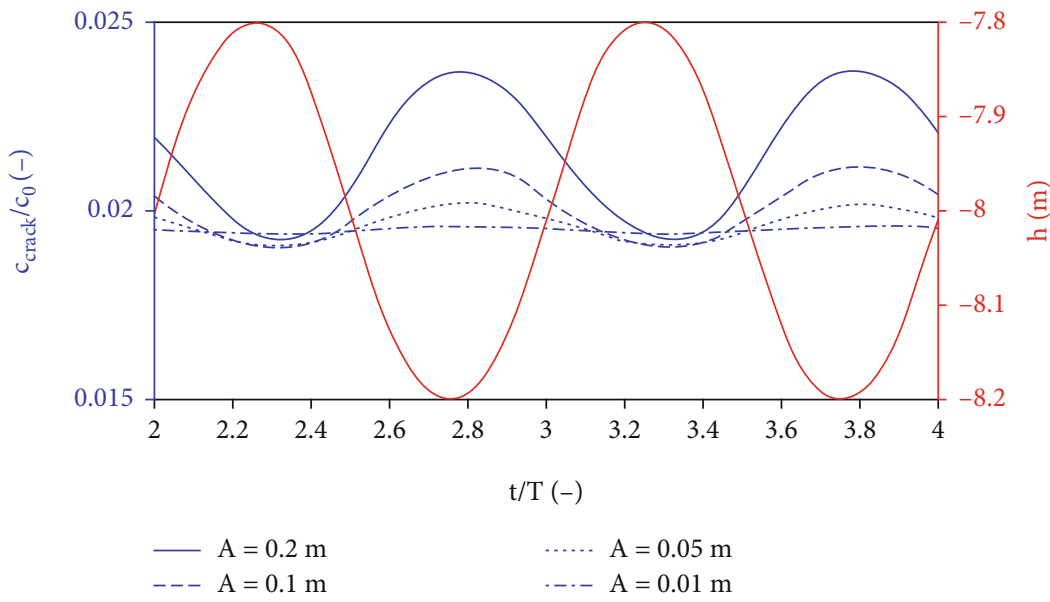

FIGURE 9: The variation of normalized gaseous TCE concentration at the crack for the cases with $T=$ one day and different fluctuation amplitudes $(A=0.01 \mathrm{~m}, 0.05 \mathrm{~m}, 0.1 \mathrm{~m}$, and $0.2 \mathrm{~m})$. The variation of the groundwater table level in the case with $A=0.2 \mathrm{~m}$ is also shown.

the concentration at the crack starts to increase sharply at 10 days after the groundwater table fluctuation. Moreover, it needs more periods to reach the dynamic equilibrium condition for the case with a shorter period. Specifically, it takes around two periods in the case with $T=$ one year, while about four hundred periods are needed in the case of $T=$ one day.

As illustrated in Figure 8(b), when the groundwater table starts to rise in the first fluctuation cycle, the concentration of gaseous TCE at the crack decreases, and the phenomenon is more obvious in the case with a larger fluctuation period. This finding is consistent with the observation in previous studies $[18,20,22]$. A rising groundwater table increases the area of high soil moisture regions, thereby inhibiting the diffusion of gaseous contaminants. On the contrary, a falling groundwater table facilitates the release of contaminants and results in a higher concentration in the vadose zone.

It is found that under the dynamic equilibrium condition, the fluctuation amplitude of the concentration at the crack increases with increasing period of the groundwater table fluctuation (see Figure 8(b)). Therefore, we only analyze the case with $T=$ one year. Figure 9 shows the TCE concentra- tion at the crack under the dynamic equilibrium condition, where $A=0.01 \mathrm{~m}, 0.05 \mathrm{~m}, 0.1 \mathrm{~m}$, and $0.2 \mathrm{~m}$ are considered. For conciseness, we only show the curve of groundwater table fluctuation with an amplitude of $0.2 \mathrm{~m}$ in the figure. It is clearly shown that there is a time lag between the fluctuations of groundwater table and concentration. The time lag is about 0.45 for all cases regardless of the fluctuation amplitude. In addition, the trend of the concentration variation is opposite to that of the groundwater table level. That is, an increasing groundwater table results in a decreasing crack concentration, and a falling groundwater table results in an increasing crack concentration.

3.4. Scenarios with Field Groundwater Fluctuations. We consider two cases with field groundwater fluctuations. The first site is located in Norfolk, Virginia [47]. The groundwater table elevations and rainfall data are provided by the Hampton Roads Sanitation District (HRSD). We choose the groundwater table data during the period between 17 September 2016 and 30 September 2016. For the reason of two heavy rainfalls, the groundwater table increased rapidly and recovered slowly to the initial 


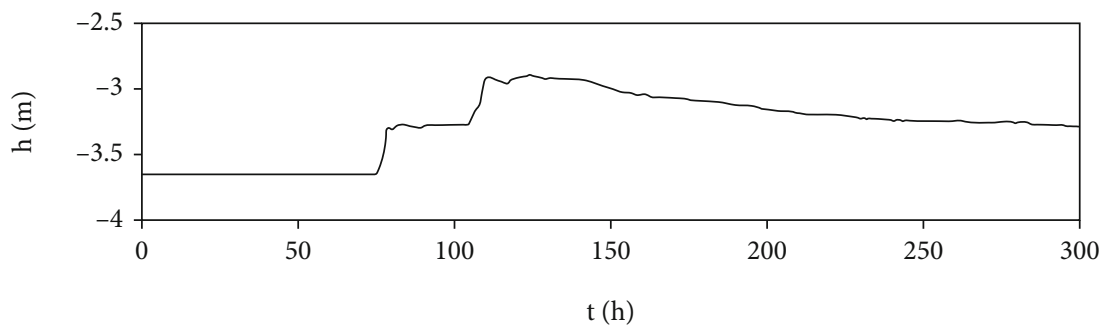

(a)

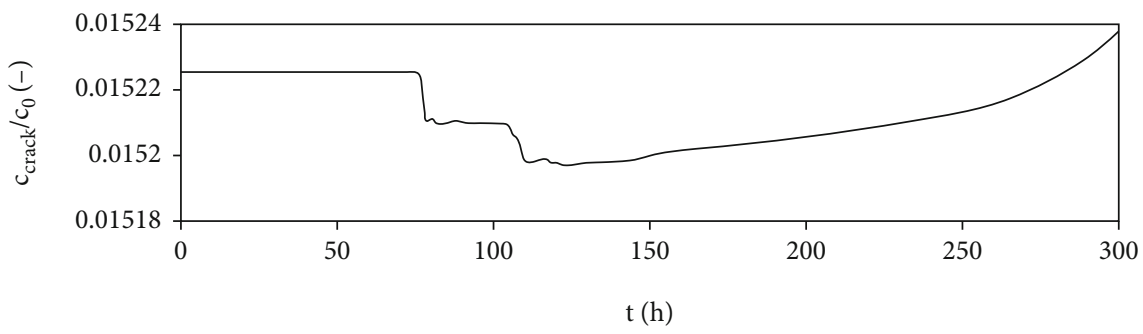

(b)

Figure 10: The groundwater table elevation data in the first site [47], and simulated normalized TCE concentrations at the crack.

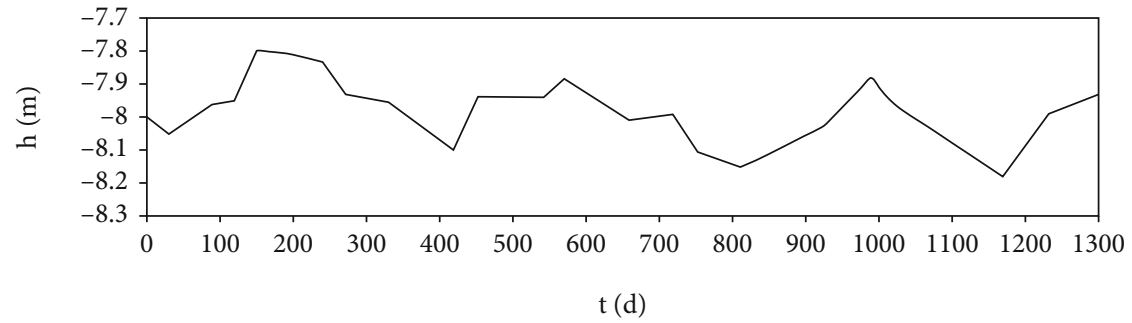

(a)

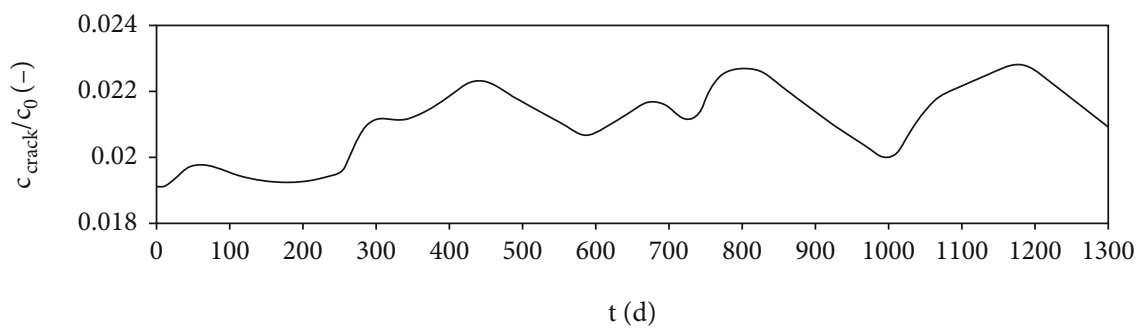

(b)

Figure 11: The groundwater table elevation data in the second site (Holton et al., [28] and Guo et al. [27]) and simulated normalized TCE concentrations at the crack.

position. Here, we explore the response of vapor intrusion to a sudden groundwater table increase. The influence of rainfall is not included in this study.

Figure 10 shows the variations of gaseous TCE concentration at the crack of the foundation in response to two heavy rainfalls. As shown, both the groundwater table and the concentration keep constant before the rain. A sudden rise of groundwater table induces the decrease of gaseous TCE concentration at the crack, since the increase of soil moisture makes it difficult for vapor to transport through the unsaturated zone. After the heavy rainfall, the groundwater table declines slowly, resulting in subsequently an increase of vapor concentration. Moreover, the concentration at the end of simulation is higher than its initial condition, which means that the sudden rise of groundwater table resulted from heavy rains will intensify the potential of vapor intrusion at large times. Our simulation results match their qualitative behavior as found above.

The second site is well described in Holton et al. [28] and Guo et al. [27]. The groundwater table elevation was collected for a period of 1300 days. The largest difference between groundwater table levels is about 0.4 meters. Here, we employ the groundwater table data to investigate its influence on vapor intrusion. Figure 11 shows the groundwater table elevation data and the transient gaseous TCE concentration at the crack. A similar trend of concentration variation as in 
the previous case can be observed. That is, a rise of the groundwater table leads to the decrease of the gaseous TCE concentration at the crack, and a drop of the groundwater table the increase of the concentration. Furthermore, we can find that a slow change (i.e., a low-frequency variation) of groundwater table has little influence on the crack concentration, as the maximum relative variation of the concentration is only around $2 \%$ in this case. This finding is consistent with that obtained above.

\section{Conclusion}

In this study, a 2D numerical model is used to explore the impact of the groundwater table fluctuation on the process of vapor transport in sandy soils. It is found that the capillary fringe offers great resistance to the migration of gaseous TCE because of its high soil moisture content for a static groundwater table. As such, a large concentration gradient can be found in the capillary fringe. However, the "block" effect of the capillary fringe will be weakened due to the groundwater table fluctuation, and more TCE vapor could migrate to the unsaturated zone from the groundwater source. Accordingly, the gaseous concentration in the vadose zone increases and results in a greater potential health risk for the people living above. The increase of gaseous TCE concentration is induced by the enhancement of diffusion and advection. Advection is the dominant mechanism in the region near the groundwater table, while diffusion plays a more important role in the transport of vapor above the range of groundwater table fluctuation.

Both the amplitude and period of fluctuation play a significant role in the migration of gaseous TCE. Generally, a higher fluctuation amplitude and a shorter fluctuation period lead to a higher concentration at the crack. A shorter fluctuation period means a higher variation rate of the groundwater table, which could cause the enhancement of mechanical dispersion and facilitate vapor intrusion. For the cases with a large fluctuation period, an obvious time lag occurs between the fluctuations of the groundwater table and the gaseous TCE concentration at the crack. Numerical results based on the field groundwater table data confirm our findings.

We acknowledge that our model setup considers periodic groundwater table fluctuations in homogeneous media and neglects the variation of gaseous TCE concentration of the source concentration and medium heterogeneities. These factors need to be considered in future investigation. Our study highlights that more attention should be paid to the groundwater table fluctuation when evaluating the potential risk of a site contaminated by volatile organic compounds.

\section{Data Availability}

The data used in this paper can be obtained upon request from the corresponding author.

\section{Conflicts of Interest}

The authors declare that they have no conflicts of interest.

\section{Acknowledgments}

Y. Ye acknowledges the financial support from the National Natural Science Foundation of China (51709085) and Fundamental Research Funds for the Central Universities (B200202158). The data used in this paper can be obtained upon request from the corresponding author.

\section{References}

[1] C. T. Green, W. T. Luo, C. H. Conaway, K. B. Haase, R. J. Baker, and B. J. Andraski, "Spatial fingerprinting of biogenic and anthropogenic volatile organic compounds in an arid unsaturated zone," Vadose Zone Journal, vol. 18, no. 1, article 190047, 2019.

[2] B. H. Liu, L. Chen, L. Huang, Y. Wang, and Y. Li, "Distribution of volatile organic compounds (VOCs) in surface water, soil, and groundwater within a chemical industry park in Eastern China," Water Science and Technology, vol. 71, no. 2, pp. 259-267, 2015.

[3] Y. Guo, P. Dahlen, and P. C. Johnson, "Development and validation of a controlled pressure method test protocol for vapor intrusion pathway assessment," Environmental Science and Technology, vol. 54, no. 12, pp. 7117-7125, 2020.

[4] P. C. Johnson and R. A. Ettinger, "Heuristic model for predicting the intrusion rate of contaminant vapors into buildings," Environmental Science \& Technology, vol. 25, no. 8, pp. 1445-1452, 1991.

[5] J. Luo, Z. Kurt, D. Hou, and J. C. Spain, "Modeling aerobic biodegradation in the capillary fringe," Environmental Science of Technology, vol. 49, no. 3, pp. 1501-1510, 2015.

[6] J. Ma, T. McHugh, L. Beckley, M. Lahvis, G. DeVaull, and L. Jiang, "Vapor intrusion investigations and decision-making: a critical review," Environmental Science and Technology, vol. 54, no. 12, pp. 7050-7069, 2020.

[7] G. Wang, Y. Xiao, J. Zuo et al., "Physically simulating the effect of lateral vapor source-building separation on soil vapor intrusion: influences of surface pavements and soil heterogeneity," Journal of Contaminant Hydrology, vol. 235, article 103712, 2020.

[8] S. Xie and E. Suuberg, "The effects of temperature and relative humidity on trichloroethylene sorption capacities of building materials under conditions relevant to vapor intrusion," Journal of Hazardous Materials, vol. 401, article 123807, 2021.

[9] Y. Yao, R. Shen, K. G. Pennell, and E. M. Suuberg, "A review of vapor intrusion models," Environmental Science \& Technology, vol. 47, no. 6, pp. 2457-2470, 2013.

[10] Y. Yao, J. Zuo, J. Luo, Q. Chen, J. Strom, and E. Suuberg, "An examination of the building pressure cycling technique as a tool in vapor intrusion investigations with analytical simulations," Journal of Hazardous Materials, vol. 389, article 121915, 2020.

[11] Z. Gribovszki, J. Szilágyi, and P. Kalicz, "Diurnal fluctuations in shallow groundwater levels and streamflow rates and their interpretation - a review," Journal of Hydrology, vol. 385, no. 1-4, pp. 371-383, 2010.

[12] J. J. Jiao and Z. Tang, "An analytical solution of groundwater response to tidal fluctuation in a leaky confined aquifer," Water Resources Research, vol. 35, no. 3, pp. 747-751, 1999.

[13] S. M. H. J. Shoushtari, N. Cartwright, P. Nielsen, and P. Perrochet, "The effects of oscillation period on groundwater 
wave dispersion in a sandy unconfined aquifer: sand flume experiments and modelling," Journal of Hydrology, vol. 533, pp. 412-420, 2016.

[14] ITRC, Vapor Intrusion Pathway: A Practical Guideline (VI-1), The Interstate Technology \& Regulatory Council, Vapor Intrusion Team, Washington, DC, 2007.

[15] USEPA, OSWER Draft Guidance for Evaluating the Vapor Intrusion to Indoor Air Pathway from Groundwater and Soils (Subsurface Vapor Intrusion Guidance), USEPA, Washington, DC, 2002.

[16] USEPA, Conceptual Model Scenarios for the Vapor Intrusion Pathway. Office of Solid Waste and Emergency Response, USEPA, Washington, DC, 2012.

[17] USEPA, OWSER Technical Guide for Assessing and Mitigating the Vapor Intrusion Pathway from Subsurface Vapor Source to Indoor. Office of Solid Waste and Emergency Response, USEPA, Washington, DC, 2015.

[18] Y. Guo, Vapor Intrusion at a Site with an Alternative Pathway and a Fluctuating Groundwater Table, Arizona State University, Phoenix, Arizona State, 2015.

[19] Y. Guo, C. Holton, H. Luo, P. Dahlen, and P. C. Johnson, "Influence of fluctuating groundwater table on volatile organic chemical emission flux at a dissolved chlorinated-solvent plume site," Ground Water Monit R, vol. 39, no. 2, pp. 43$52,2019$.

[20] K. A. McCarthy and R. L. Johnson, "Transport of volatile organic compounds across the capillary fringe," Water Resources Research, vol. 29, no. 6, pp. 1675-1683, 1993.

[21] D. Werner and P. Höhener, "The influence of water table fluctuations on the volatilization of contaminants from groundwater," in Groundwater Quality: Natural and Enhanced Restoration of Groundwater Pollution, S. F. Thornton and S. E. Oswald, Eds., pp. 213-218, International Association of Hydrological Sciences, Sheffield, UK, 2002.

[22] S. Picone, J. Valstar, P. van Gaans, T. Grotenhuis, and H. Rijnaarts, "Sensitivity analysis on parameters and processes affecting vapor intrusion risk," Environmental Toxicology and Chemistry, vol. 31, no. 5, pp. 1042-1052, 2012.

[23] N. R. Thomson, J. F. Sykes, and D. V. Vliet, "A numerical investigation into factors affecting gas and aqueous phase plumes in the subsurface," Journal of Contaminant Hydrology, vol. 28, no. 1-2, pp. 39-70, 1997.

[24] C. Lu, P. K. Kitanidis, and J. Luo, "Effects of kinetic mass transfer and transient flow conditions on widening mixing zones in coastal aquifer," Water Resources Research, vol. 45, article W12402, 2010.

[25] S. Qi, J. Luo, D. O'Connor, X. Cao, and D. Hou, "Influence of groundwater table fluctuation on the non-equilibrium transport of volatile organic contaminants in the vadose zone," Journal of Hydrology, vol. 580, article 124353, 2020.

[26] A. Vallejos, F. Sola, and A. Pulido-Bosch, "Processes influencing groundwater level and the freshwater-saltwater interface in a coastal aquifer," Water Resources Management, vol. 29, no. 3, pp. 679-697, 2015.

[27] Y. Guo, C. Holton, H. Luo et al., "Identification of alternative vapor intrusion pathways using controlled pressure testing, soil gas monitoring, and screening model calculations," Environmental Science \& Technology, vol. 49, no. 22, pp. 1347213482, 2015.

[28] C. Holton, H. Luo, P. Dahlen, K. Gorder, E. Dettenmaier, and P. C. Johnson, "Temporal variability of indoor air concentra- tions under natural conditions in a house overlying a dilute chlorinated solvent groundwater plume," Environmental Science \& Technology, vol. 47, no. 23, pp. 13347-13354, 2013.

[29] Y. Yao, Y. Xiao, F. Mao, H. Chen, and I. Verginelli, "Examining the role of sub-foundation soil texture in chlorinated vapor intrusion from groundwater sources with a two-layer numerical model," Journal of Hazardous Materials, vol. 359, pp. 544553, 2018.

[30] K. G. Pennell, O. Bozkurt, and E. M. Suuberg, "Development and application of a three-dimensional finite element vapor intrusion model," Journal of the Air \& Waste Management Association, vol. 59, no. 4, pp. 447-460, 2012.

[31] R. Shen and E. M. Suuberg, "Impacts of changes of indoor air pressure and air exchange rate in vapor intrusion scenarios," Building and Environment, vol. 96, pp. 178-187, 2016.

[32] Y. Yao, F. Mao, S. Ma, Y. Yao, E. M. Suuberg, and X. Tang, "Three-dimensional simulation of land drains as a preferential pathway for vapor intrusion into buildings," Journal of Environmental Quality, vol. 46, no. 6, pp. 1424-1433, 2017.

[33] Y. Yao, Y. Wang, Z. Zhong, M. Tang, and E. M. Suuberg, "Investigating the role of soil texture in vapor intrusion from groundwater sources," Journal of Environmental Quality, vol. 46, no. 4, pp. 776-784, 2017.

[34] M. T. van Genuchten, "A closed-form equation for predicting the hydraulic conductivity of unsaturated soils," Soil Science Society of America Journal, vol. 44, no. 5, pp. 892-898, 1980.

[35] J. C. Parker, R. J. Lenhard, and T. Kuppusamy, "A parametric model for constitutive properties governing multiphase flow in porous media," Water Resources Research, vol. 23, no. 4, pp. 618-624, 1987.

[36] R. J. Millington and J. P. Quirk, "Permeability of porous solids," Transactions of the Faraday Society, vol. 57, p. 1200, 1961.

[37] L. D. V. Abreu and P. C. Johnson, "Effect of vapor sourcebuilding separation and building construction on soil vapor intrusion as studied with a three-dimensional numerical model," Environmental Science \& Technology, vol. 39, no. 12, pp. 4550-4561, 2005.

[38] USEPA, User's Guide for the Johnson and Ettinger (1991) Model for Subsurface Vapor Intrusion into Buildings. Office of Emergency and Remedial Response Toxics Integration Branch, USEPA, Washington, DC, 1997.

[39] W.-T. Joun, S.-S. Lee, Y.-E. Koh, and K.-K. Lee, "Impact of water table fluctuations on the concentration of borehole gas from NAPL sources in the vadose zone," Vadose Zone Journal, vol. 15, no. 4, 2016.

[40] C. Barber, G. B. Davis, D. Briegel, and J. K. Ward, "Factors controlling the concentration of methane and other volatiles in groundwater and soil-gas around a waste site," Journal of Contaminant Hydrology, vol. 5, no. 2, pp. 155-169, 1990.

[41] R. Shen, K. G. Pennell, and E. M. Suuberg, "Influence of soil moisture on soil gas vapor concentration for vapor intrusion," Environmental Engineering Science, vol. 30, no. 10, pp. 628637, 2013.

[42] Y. Yao, F. Mao, Y. Xiao, and J. Luo, "Modeling capillary fringe effect on petroleum vapor intrusion from groundwater contamination," Water Research, vol. 150, pp. 111-119, 2019.

[43] G. B. Davis, J. L. Rayner, M. G. Trefry, S. J. Fisher, and B. M. Patterson, "Measurement and modeling of temporal variations in hydrocarbon vapor behavior in a layered soil profile," Vadose Zone Journal, vol. 4, no. 2, pp. 225-239, 2005. 
[44] H.-P. Guo and J. J. Jiao, "Numerical study of airflow in the unsaturated zone induced by sea tides," Water Resources Research, vol. 44, no. 6, p. 44, 2008.

[45] K. You and H. Zhan, "Comparisons of diffusive and advective fluxes of gas phase volatile organic compounds (VOCs) in unsaturated zones under natural conditions," Advances in Water Resources, vol. 52, pp. 221-231, 2013.

[46] N. Cartwright, "Moisture-pressure dynamics above an oscillating water table," Journal of Hydrology, vol. 512, pp. 442-446, 2014.

[47] B. D. Bowes, J. M. Sadler, M. M. Morsy, M. Behl, and J. L. Goodall, "Forecasting groundwater table in a flood prone coastal city with long short-term memory and recurrent neural networks," Water, vol. 11, no. 5, p. 1098, 2019. 